\title{
Main Components of Virtual Educational Environments
}

\author{
Vinichenko V.A. ${ }^{1,2}$ \\ ${ }^{1}$ Novosibirsk State Technical University, 20, K. Marx street, Novosibirsk, 630073, Russia \\ ${ }^{2}$ Siberian State University of Water Transport, 33 Tshchetinkina street, Novosibirsk, 630099, Russia \\ *Corresponding author.Email: vika_06.07@mail.ru
}

\begin{abstract}
The author explores the problem of forming a virtual educational environment. The purpose of the article is to identify the main components necessary for creating a virtual educational environment.

The methodological basis of the study was a comparative analysis of educational institutions from different countries of the world, the historical and descriptive method made it possible to identify the reason for the inconsistency of current architecture with the requirements of modern educational conditions. A review of scientific publications from Denmark, Australia, the Republic of Kosovo, USA, Norway, and Israel has allowed us to formulate a number of trends emerging on the world stage in higher education.
\end{abstract}

Keywords: virtual and augmented reality, virtual educational environment, visual literacy, digital natives,

smart materials, artificial intelligence

\section{INTRODUCTION}

The modern education system provides superficial training, often associated with ticking, and the employer's needs are focused on problem-solving skills, critical thinking, team building and a practice-oriented character [5].

In order to meet the demands of employers, higher education is increasingly introducing digital technologies in the form of virtual learning environments. Many universities are massively opening online courses (MOOCs), and video conferencing systems offer multimodal learning that goes beyond time and space [13]. As digitalization penetrates deeper and deeper into all sectors of society, including the educational sector, the demand for the integration of digital technologies with educational technologies becomes more and more obvious. There is no doubt that education will continue to be seen as an environment for solving economic and social problems [14].

There is a dynamically growing demand for new training formats that are capable of shaping critical thinking, skills for solving complex problems in conditions of risk and uncertainty, and communication skills.

The primary goal of including digital technologies in the educational process is to increase the effectiveness of education, reduce the classroom load on teachers, attract more students, and also prepare a graduate for real work without special training.

Digital technologies are able to develop, limit or transform the educational process [14].

\subsection{Conditions for the inclusion of digital technology in the educational process}

The introduction of digital technology can significantly improve the quality of education. However, there is still a large category of people who are within the framework of the concept of "digital exclusion", that is, exclude digital technology from everyday activities.

An author from Denmark [14] identified a number of factors affecting digital exclusion (Figure 1).

When introducing innovations in the educational sphere, it is necessary to take into account the historical experience of reforming one of the most conservative sectors of the national economy.

The emergence of new technologies in the field of education is usually associated with increased expectations from leadership and skepticism from teachers. After the introduction of technology, for various reasons, a comparison of expectations and reality occurs, which in some cases leads to disappointment. As they either implemented it incorrectly, or did not learn how to use it, or understaffed it, paying tribute to the fashion of modern devices.

Many educational institutions are adequately equipped for the full integration of digital technologies in the educational process, but their use is limited.

The results of a study by the International Association for the Assessment of Educational Achievements (ICILS) indicate the presence of the highest level of computer literacy among Norwegian students [12]. 


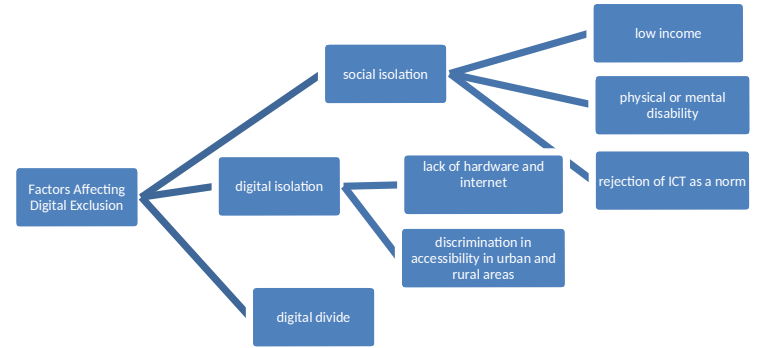

Figure 1 Factors Affecting Digital Exclusion

At the same time, $75 \%$ of Norwegian students use computers at home daily, and only $8 \%$ in the educational environment [4].

The reason for the lack of integration of digital and pedagogical technologies may be due to the influence of two factors [6]:

- availability of technical resources, installation and maintenance of software, training and consulting support. A very important factor is the easiness and speed of access to the computer: in case access is difficult - the teacher will somehow avoid its inclusion in the educational process;

- habits, perception and level of perceived value of digital technology for educational purposes, a sense of usefulness for educational purposes [13].

The authors Saari and Säntti [9] argue that the teacher should take into account the historical, ideological and social characteristics of specific educational institutions, as well as the level of existing technologies, in the structure of the reasons for the incomplete inclusion (or even failure) of digital technologies in their educational process. An author from the United States in his study shows a significant correlation between family income, parental education, and the likelihood of a home computer and Internet access [14].

To use digital technologies in education, a teacher must possess not only special knowledge in the subject, the ability to effectively use digital technologies both in everyday life and in classroom work, motivation to participate in digital culture, as well as technical skills related to computer literacy. The totality of such knowledge is called digital competency [9].

\subsection{Digital Natives and Digital Immigrants}

The author first coined the term "digital native", meaning by this those representatives of the digital generation who were born between 1980 and 1994 .

This category of the population provides training with the help of digital technologies with particular ease. People born before 1980 got the name from Mark Prensky "digital immigrant". Those that are less adapted to the digital learning environment were born before 1980 .

An experiment was performed at Ballarat University, located in Australia: about 150 students studying in the Nursing department had to work on creating a two-minute video within 12 weeks. The content of the video was to demonstrate the mastery of a number of competencies related to vital indicators.

After that, they uploaded a video on YouTube for evaluation by subject teachers and netizens.

Then, the feedback was received from viewers of the video, where such parameters as the subject and presentation of the material by a specific author were evaluated.

Using the YouTube tool as a complement to education is no longer an innovation.

However, its use allows for the more active involvement of "Digital Natives" in the educational process, while increasing the level of digital literacy of "digital Immigrants".

YouTube allows you to bridge the gap between generations of digital natives and immigrants, provide modern methods of evaluation through getting likes, clicks, etc.

A number of students reflected the usefulness of using YouTube in the learning process.

At the same time, in order to supply educational material to the general public, the student must master the material more deeply, which is the ultimate goal of studying the discipline.

Despite the fact that most of the students belong to the category of digital Natives, they pointed out the complexity of using this medium when creating a video [2].

\section{VIRTUAL EDUCATIONAL ENVIRONMENT COMPONENTS}

\subsection{AR and VR}

In the context of higher education, ICTs are being introduced in the form of virtual learning environments, augmented reality and virtual reality.

Today, reality and virtuality are no longer opposed. Their ever closer relationship gives modernity such attributions as heterogeneity, complexity, plasticity, ambiguity, mobility, speed, uncertainty. Their combination, noticed at the beginning of the new millennium by the famous sociologist Zygmunt Bauman, formed the basis of a new metaphor that defines our society: fluid modernity.

Augmented reality or AR, as it is usually called, is a technology that allows you to complement the real world with virtual objects in such a way that the real and virtual are presented as one [15]. AR includes virtual reality (VR), 360-degree video and holograms that combine physical and digital measurements.

For the first time, augmented reality technology was included in the educational process in the 1990s. However, AR has gained particular popularity in recent years.

The number of scientific articles (WoS) devoted to augmented reality research for the period up to 2014 is 77 articles, while for the period from 2014 to date, 242 
articles have been published. Such interest of the scientific community in this technology proves the relevance of the introduction of digital technologies in the educational process [15].

One of the most common educational tools using augmented reality is AR-books. AR-books is a physical book that contains images that, when the camera scans the device and recognizes the AR application, launches the display of augmented resources, including images, video clips and 3D models in the form of overlays on the screen. AR applications are widely used in various fields of life, but

Table 1 Advantages and Disadvantages of Using Mobile AR in Learning

\begin{tabular}{|l|l|}
\hline Advantages & Disadvantages \\
\hline - student engagement and performance are enhanced; & $\begin{array}{l}\text { - technological limitations on existing } \\
\text { equipment; }\end{array}$ \\
\hline $\begin{array}{l}\text { - increasing the freedom of action of students in terms of the formation of } \\
\text { their individual learning paths; }\end{array}$ & - the high cost of equipment and software; \\
\hline - there is an increase in students' independence; & $\begin{array}{l}\text { - software products are often of poor quality due } \\
\text { to lack of experience in development; }\end{array}$ \\
\hline - there is an additional reason for interaction and partnership; & - an user interface is not always convenient; \\
\cline { 1 - 1 } - a positive attitude towards learning is being developed. & \\
\hline
\end{tabular}

The advantages of AR systems when interacting with other technologies, such as individual learning profiles, sensory feedback, which can

make an analysis of physiological reactions, as well as artificial intelligence, which can analyze student learning and change their learning path.

\subsection{Artificial Intelligence}

Artificial intelligence (AI) is also actively used in education. AI is usually defined as machine intelligence, which is demonstrated by an inanimate being.

At the same time, it is worth noting that over the past 30 years, AI has been offered many times, however, it has not been widely used.

AI can be useful for the educational sector by its ability to analyze digitized data. The ability to use geolocation data from mobile devices about places, time and duration of visits, reading physiological parameters from devices like Apple Watch will allow AI to provide highly personalized training in real time.

However, it is essential to slow down the further development of AI in this area of ensuring the security of personal data more than $40 \%$ of them are designed specifically for education [11].

The interest in learning based on augmented reality games (ARGBL) is gradually increasing. For example, authors propose engaging students through emulating the success of AR games such as Pokemon GO!

The authors' studies showed that when using mobile AR, a number of advantages and disadvantages are formed (Table 1).

\subsection{Competencies of the virtual educational environment}

\subsubsection{Visual literacy}

The Israel Institute of Technology (Technion) simultaneously solves three problems:

- development and implementation of educational programs with the inclusion of employers and social partners in the educational process;

- emphasis on training right at the workplace;

- the attraction of potential employers to the teacher in order to keep industry knowledge up to date [17].

In other words, the Technion implements the concept of CDIO (Conceive - Design - Implement - Operate) or the "Think - Design - Implement - Manage" model. The concept involves reducing the distance between theory and practice in engineering education.

The CDIO Initiative international project was launched back in 2000 as part of the reform of engineering education. For technical specialties, it is very important to have visual literacy. The IEEE standard (Institute of Electrical and Electronic Engineers), which is one of the most important institutes for the training of technical specialists, points to "... the importance of visualizing objects, translating ideas into drafts...". At present, digital natives absorb most of the information visually. therefore, for a person living in the modern world, visual literacy is becoming a critical competency along with digital [16]. 
The authors of [17] in their work put forward and prove a hypothesis about the development of visual literacy using $3 \mathrm{D}$ printing. Equipped with a $3 \mathrm{D}$ printer and LEGO designer kits, the Technion laboratory is in high demand for educational programs because it allows you to create visual literacy directly in action, as close as possible to professional activity. Experts from the civil, aviation and electrical industries apply for knowledge. The 3D printer training course, together with the LEGO designer, is also included in the training program for teachers of mathematics and physics.

\subsubsection{Digital literacy}

Digitalization is one of the processes in the development of which, one cannot ignore the historical features of the development of a country. This means that the level of digital literacy and the spread of digital technologies will differ (in some cases, significantly) depending on the level of development of the country itself [10].

In this regard, authors from Kosovo conducted a survey on what is the degree of digitalization in public and private institutions, in particular, higher education institutions. Among 168 respondents, a survey was conducted on what technologies are used in education: electronic libraries, mobile technologies, artificial intelligence, etc.

To promote their own educational programs, most universities use social networks. Moreover, it was noted that state universities use digital technologies to a lesser extent than private ones. The authors of [10] attribute this to less flexibility in terms of financial planning at state universities, as well as fewer investments in marketing campaigns.

Electronic libraries in private universities in Kosovo use $35 \%$ of respondents, while in public universities this figure is $3.2 \%$.

The authors [7] point to the need to include elements of virtual education in industries that are vital to humans. The

Table 2 Comparative analysis of the use of digital technologies in public and private universities, $\%$

\begin{tabular}{|l|c|c|}
\hline \multicolumn{1}{|c|}{ Indicator } & State & Private \\
\hline Use of electronic libraries & 3.2 & 35 \\
\hline $\begin{array}{l}\text { The presence of a digital development } \\
\text { strategy }\end{array}$ & 9 & 48 \\
\hline $\begin{array}{l}\text { The assumption that ICT is an } \\
\text { opportunity for further development }\end{array}$ & 60 & 40 \\
\hline Using Cloud Services & 24 & 48 \\
\hline
\end{tabular}

\subsection{Virtual Education Environment Architecture}

As can be seen from the set of digital tools used in teaching practice, the architecture of existing universities
The $3 \mathrm{D}$ printer and constructor in this case is one of the technologies of active learning, expanding the boundaries of the usual format for obtaining knowledge. What becomes especially valuable within the framework of the CDIO concept, which contains a high potential in the development of modern teaching technologies. In such a learning environment, students perceive, process and visualize a much larger number of objects than in an ordinary classroom [17].

development of production processes on simulators and simulators using VR technology has become an integral part of teaching practice.

This is especially true for such a parameter as labor productivity. Currently, hydrocarbon prices are declining in global markets, and therefore, profitability can only be achieved by increasing labor productivity. This required the introduction of virtual (VR) and augmented (AR) technologies into the educational process. The above tools significantly reduce the time and cost of training.

Virtual training will teach engineers, technicians, and operators to safely commission industrial equipment.

Xie developed the Onew 360 gas-metal arc welding simulator [18]. The virtual reality simulator contains a camera where the student sees the welding torch, the audio speakers create sound effects, creating the realism of the process of welding the seam.

Power engineers are actively using this form of training when practicing maneuvers with work for high, medium and low voltage underground distribution networks. This form of training provides security. 
However, the key problem was not only the architecture of the classrooms, some problems were caused by the low quality of instruction in such classes due to the increased noise level, the accumulation of a large number of students in one place and the lack of teachers who were ready to take classes in such conditions [15].

Many teachers adhere to the "paradigm of one": [8] "... one teacher teaching one subject in one class to students of the same age using one curriculum at one pace for one hour" (p. 13).

In this regard, many classrooms abandoned the idea of open classes, returning to the traditional format.

In the period 2003-2010, the Department of Education and Skills (DfES) again proposed an initiative to create open classes.

The authors of [1] suggest that designing open classes should be based on the principles of multifunctionality, mixing physical and virtual space. During the construction of such structures, new smart materials should be used: for example, smart concrete. Which allows to detect cracks, a smart brick that allows you to transfer information about humidity and temperature, smart glass turning from transparent to opaque, creating individual areas for work. Smart materials can eliminate pre-existing problems with lighting, noise levels, etc.

In addition to ease of use, such materials take into account public concerns about climate change and UN requirements in the area of sustainable development until 2030.

Authors from Australia [1] studied the experience of teachers working in open classes. It was found that open spaces allow educators to develop dynamically, since with such training formats, it is necessary to reconstruct the usual temporal and spatial framework.

In addition, work in open spaces, which are contrasted with classrooms of the industrial era, does not imply anything individual since all teachers work with the same materials, tools. As a result of such interaction, the level of informal interaction between teachers increased.

The result of training in open spaces is the reduction of the distance between the student and the student, and individual forms of thinking are transformed into network forms of interaction.

\section{CONCLUSION}

The study of digital technologies used to train specialists in various industries has led to the conclusion about the universality of their application in order to increase labor productivity, the quality of education while reducing the time and cost of the educational process.

As a result of the study, the main components of the virtual educational environment were identified, to which the author relates:

- digital and visual literacy of users;

- the use of artificial intelligence in building individual educational trajectories;
- mandatory restructuring of university architecture to the needs of digital tools;

- availability of open online courses (MOOC);

- the release of teachers from part of the classroom load in favor of research work, participation in professional virtual communities;

- practical orientation of training;

- safe development of skills in technologically complex processes.

\section{REFERENCES}

[1] Alterator and Deed (Alterator, S., \& Deed, C. (2013). Teacher adaption to open learning spaces. Issues in Educational Research, 23(3), 315-330.

[2] Andrew Smith, Blake Peck. The teacher as the 'digital perpetrator': Implementing web 2.0 technology activity as assessment practice for higher education Innovation or Imposition? Procedia Social and Behavioral Sciences 2 (2010) 4800-4804. DOI: https://doi.org/10.1016/j.sbspro.2010.03.773 .

[3] Bacca, J., Baldiris, S., Fabregat, R., Graf, S., \& Kinshuk (2014). Augmented reality trends in education: A systematic review of research and applications. Educational classroom, in: Futures 113 (2019) 102422. DOI: https://doi.org/10.1016/j.futures.2019.04.009.

[4] Elen J. Instefjord, Elaine Munthe. Educating digitally competent teachers: A study of integration of professional digital competence in teacher education, in: Teaching and Teacher Education 67 (2017) 37-45. DOI: https://doi.org/10.1016/j.tate.2017.05.016.

[5] Elliot, B. (2008) Assessment 2.0: Modernising assessment in the age of Web 2.0. Scottish Qualifications Authority. Retrieved 20/10/08 from http://www.scribd.com/doc/461041/Assessment-20.

[6] Ertmer, P. A. (1999). Addressing first- and secondorder barriers to change: Strategies for technology integration. Educational Technology Research and Development. 1999. 47(4), pp.47-61. DOI: https://doi.org/10.1007/BF02299597.

[7] Garcia C.A., Naranjo J.E., Ortiz A., Garcia M.V. An Approach of Virtual Reality Environment for Technicians Training in Upstream Sector. IFAC PapersOnLine 52-9 (2019) 285-291. DOI: https://doi.org/10.1016/j.ifacol.2019.08.222 .

[8] Hood, D. (2015). The Rhetoric and the Reality: New Zealand Schools in the 21st Century. Masterton, New Zealand: Fraser Books. 
[9] Ilomäki, Liisa \& Kantosalo, Anna \& Lakkala, Minna. (2011). What is digital competence? In Linked portal. Brussels: European Schoolnet. http://linked.eun.org/web/guest/in-depth3.

[10] Limani Y., Hajrizi E., StapletonL., Retkoceri M. Digital Transformation Readiness in Higher Education Institutions (HEI): The Case of Kosovo. IFAC PapersOnLine 52-25 (2019) 52-57. DOI: https://doi.org/ 10.1016/j.ifacol.2019.12.445 .

[11] Lytridis, C., Tsinakos, A., \& Kazanidis, I. (2018). ARTutor - an augmented reality platform for interactive distance learning. Education Sciences; Basel, 8(1), 6., p. 2.

[12] Ottestad, G., Throndsen, I., Hatlevik, O., \& Rohatgi, A. (2014). Digitale ferdigheter for alle? Norske resultater fra ICILS 2013 [Digital literacy for all? Norwegian results from ICILS 2013]. Oslo: Senter for IKT i utdanningen [The Norwegian Centre for ICT in Education].

[13] Saari, A., \& Säntti, J. (2017). The rhetoric of the 'digital leap' in Finnish educational policy documents. European Educational Research Journal, 17(3), 442457.

[14] Saifuddin Khalid, Md., Pedersen Mette Jun Lykkegaard. Procedia - Social and Behavioral Sciences $228 \quad$ (2016) $614 \quad-\quad 621 . \quad$ DOI: https://doi.org/10.1016/j.sbspro.2016.07.094 .

[15] Sean M. Leahy, Charlotte Holland, Francis Ward. The digital frontier: Envisioning future technologies impact on the classroom, in: Futures 113 (2019) 102422.

DOI: https://doi.org/10.1016/j.futures.2019.04.009.

[16] Shelton, B. E., \& Hedley, N. R. (2002). Using augmented reality for teaching earth-sun relationships to undergraduate geography students. The First IEEE International Technology \& Society, 17(4), 133-149.

[17] Vernera I., Merksamer A.. Digital design and 3D printing in technology teacher education. Procedia CIRP $36 \quad$ (2015). pp.182-186. DOI: https://doi.org/10.1016/j.procir.2015.08.041 .

[18] Xie,B.,Zhou,Q.,Yu,L.,2015.Areal-time welding training system base on virtual reality, in: 2015 IEEE Virtual Reality (VR). Presented at the 2015 IEEE Virtual Reality (VR), IEEE, Arles, Camargue, Provence, France, pp. 309-310. DOI: https://doi.org/10.1109/VR.2015.7223419. 